\title{
Micro-environments in Libraries for Young Children
}

\author{
Stamoulia Polyzou*, Nikos Zygouris, Kafenia Botsoglou, George.I Stamoulis, Denis Vavougios \\ University of Thessaly \\ Lamia, Greece \\ ${ }^{*}$ Corresponding author's email: apolyzou [AT] uth.gr
}

\begin{abstract}
Most public libraries, small, medium, or large, offer a variety of services, facilities and amenities to their audience, depending on the assigned functions. The ideal size of space for children in public libraries cannot be calculated according to the population that it will serve, as is often the case with school libraries, but based on the activities to be developed and the characteristics of particular characteristics of childhood. Therefore, emphasis must be given primarily on the qualitative and secondarily on the quantitative characteristics of the children's library physical environment. This paper presents answers on some basic questions. Do Public Libraries provide special space arrangements for children and their families in their establishments? Are Children Libraries "reading-rooms" suitably designed and furnished as to provide the necessary areas for reading, relaxing, playing or creating? Observations in several library facilities revealed some interesting findings concerning Children's Library environments.
\end{abstract}

Keywords-Children's Library space micro-environment, Children's Library furniture, Children's Library space variety

\section{INTRODUCTION}

In most cases, there is no single answer to the question 'how should the space of a child-friendly library look like neither there is there is 'one-size-fits-all' library image [1]. Steele's rule determines that [2], we organize the space around us according to what we intend to do with it. A similar position is found in the IFLA Guidelines for library services for children aged 0-18 [3], according to which although "there are no universal standards for the size and design of children's libraries facilities" the library should consider providing space for the practices usually developed in the library, namely reading, playing, creating, and meeting with other families and friends. Micro-environments are considered a flexible solution for this variety of activities [4].

This study examined whether public libraries can provide young children and families with variety of microenvironments, one basic environmental space characteristic. We decided to check two dimensions of children's library space variety of microenvironments a) the hard and soft dimension and b) interaction and withdrawal.

The findings revealed that all Children Library Departments and all Children Library spaces provide a 'hard' area with tables and chairs but not necessarily a 'soft' space. Moreover, users can always find an interaction space, but a withdrawal space is hard to find or even to create.

\section{CHILDREN'S LIBRARY SPACES}

Most children library spaces, small, medium, or large, offer a variety of services, facilities, and equipment to their users, depending on the assigned functions. In general, the main services that libraries offer to their public, within their space are the following: a) information, b) lending, c) reading room/s, d) computer and internet use, e) programs and events.

The ideal size of space for children in public libraries cannot be calculated according to standards based on the number of users to be served, as it can be estimated in school libraries. Instead, as Anastasakis argues [5], apart from determining the basic space needed per child who uses the library without participating in an activity (1.5 $\left.\mathrm{m}^{2} / \mathrm{child}\right)$, the primary criterion with which the required space can be calculated is based on the activities to be developed and the characteristics of childhood. Therefore, in addition to determining the minimum requirements in space and equipment, emphasis should be placed primarily on the qualitative and secondarily to the quantitative characteristics of the physical environment [6]. 
Beyond its demarcation the space layout provides children with information about the activities that can be developed, whereas at the same time it also determines, and indicates the positions that individuals can occupy and generally use. In a multipurpose space, a clear space demarcation and the possibility of using one area, without creating a problem in another, is a matter of good organization.

As in every interior space, library space organization depends primarily on its structural surfaces (e.g., surfaces, walls), on the non-structural ones (e.g., furniture, other equipment), as on their different provisions, which define separate possibilities.

Open floor plan design layout, most common in libraries, allows the environment to be transformed and stimulates interest and willingness to explore [7]. In contrast to these advantages, an open floor plan designed library may result in increased activity; impede concentration and self-concentration, and even encouraging aggression [8, 9]. An appropriate solution to the above problem is the separation of open spaces into smaller areas. Thus, fewer people can be gathered and overcrowding, which often leads to high noise levels, may be avoided. The separation of quieter and noisier areas is always a useful combination for children and users who seek relaxation and calmness, or conversely, participation in activities and interaction with others.

Among structural solutions for designing a multifunctional space is the creation of levels. Levels provides surfaces on which children can read, develop a brick construction toy, a board, or a role play. In addition, reading steps is always suitable for hosting individuals or a small children's group playing or attending a show or any other event. According to Gibson [10], stairs are suitable for sitting but at the same time call for movement (ascent, descent), as well as, for viewing from above. This particular possibility of viewing from above, according to Curtis and Carter [11], offers not only the opportunity of different viewing, but also the experience of perceiving the body in different dimensions. Undoubtedly, although multi-level spaces have the advantage of creating small areas, flat spaces are also desirable because they perform better in terms of access and security.

Besides walls and permanent structural surfaces other inventive solutions can contribute to the formation of areas such as stable dividers, fixed or movable furniture. A simple backless bookshelf for example, positioned between the tables and another space allows such a formation.

Among other non-structural ways to zone indoor environments is the use of soft materials such as carpets, cushions, small mattresses, and other non-binding objects that children can use in any combination, in order to create a comfortable place for relaxation.

Finally, the use of various color stimuli and special lighting settings may result in a visual and aesthetic organization of the space, which in turn stimulates the senses and maintains interest in a place [4, 12, 13]. Alternations such as light and dark, outside and inside, quiet and noisy, are key qualities of the variety of children's spaces that create microenvironments [14].

Children's library space is organized in different ways. Initially, it is organized to support interaction of the people who live in it, users and personnel. In this case, space is divided in operating areas without a specific theme, intended for their use by individuals, small or large groups. At a second level, the space allows for the creation of activity areas which are supported by appropriate equipment (e.g., area with tables and chairs for reading, writing and other activities, computer area). At a third level, in the library children may find corners or learning stations to play and to develop specialized skills $[4,15]$. The number of children that can use an area at a time is often implicitly determined by the number of seats or the range of equipment [8].

A rule developed by Blaska and Hasslen [16] when studying Swedish preschools can also apply in library spaces for children. In the children's environment five dimensions must be in harmony. The soft and the hard, the open and the closed, the low and the high mobility, the coexistence and the withdrawal, the existence of simple, complex, and more complex materials that can spark the interest of the children. According to the researchers [16], any of the dimensions each edge may be suitable at times, the chronic imbalance between them should be a cause for concern.

With the "hard" area (table area) being necessary for a lot of creative work in the library (e.g., writing, painting, construction, etc.), the presence of tables, non-soft seats, marble, or tile floor must be balanced with the presence of a "soft" area. Due to the wide range of activities that the "soft" areas can serve (e.g., reading, browsing, talking, listening to stories, playing, relaxing, and standing with a variety of postures) they are considered very crucial. 'Soft' spaces may be offered either at one point, e.g., in a space covered by a thick rug or scattered throughout the Children's Department or the Children's Library allowing children to find the arrangements that best suit them, -whether concerning individuals or groups. Play, socializing and the need for interaction, communication and bonding are key features of individuals [17]. Softness is preferred as one of the prominent feature of the library space, as the creation of a suitable environment for reading depends on it [18]. Softness can be created with the use of temporary elements in the space, such as curtains, cushions, carpets but also with the presence of plants and other decorative elements that contribute to the creation of a "home" environment [16]. 
In the opposite of these needs stands the need to withdraw from the space of coexistence with other people, from an activity or a situation. Withdrawal "in a space within space" is certainly not the only way to make a child inaccessible. By reading, distant, or apathetic behavior can also achieve the withdrawal it seeks in order to refresh its forces and return renewed to the social environment [8]. Nevertheless, research shows that children prefer areas, recesses, or structures in which they can find "shelter" or limit their social interaction [19]. Often, they intervene in a space in order to create a protected space for their game [20].

\section{PROBLEM STATEMENT}

In most cases, the question "what should a child-friendly library space look like" does not have a single answer. As Dewe points out, "there is no one-size-fits-all library image" [1], while Steele's rule determines that we organize the space around us according to what we intend to do with it [2]. A similar position can be traced in the IFLA Guidelines for library services to children aged 0-18, [21], according to which although "there are no global standards for the size and design of children's libraries", the space of the library owes to:

- offer welcome messages

- provide sufficient space for the collections, promotion and practices developed in the space by both the public and the staff

- be appropriately designed for the age range it serves but also for all library users, including people with disabilities

- create micro-environments

- facilitate the user to perform a task (support autonomy)

- be flexible, to allow a variety of activities

- $\quad$ suggest differentiated options for all ages

- enhance besides cognitive, social, and emotional learning

- maintain appropriate environmental conditions

- be safe

Overall, the children's library space should be designed in such a way, so as to offer opportunities and promote decision making. Autonomous access to a rich collection, the choice of activity through a variety of offered activities, the possibility of easy movement in space, opportunities to interact with other children, with parents and staff, the ability to reflect and contemplate are features of a child-centered learning space.

In this research, we aimed to examine whether library spaces devoted to children create the necessary microenvironments for the most common children's library practices ; mainly reading, playing, creating. Thus, the main question was if one basic, quality environmental characteristic is offered: variety of micro -environments. Specifically, we set out to look whether children's library spaces demonstrate two dimensions of variety: a) the hard and the soft, b) the interaction and the withdrawal.

\section{Method}

The mapping of Libraries offering on-site services to children "in a suitable designed and accordingly equipped area, room, or in a separate accommodation capable to create the appropriate conditions for the stay and activity of children, while meeting both their capabilities and needs" was a prerequisite for participating in the $1^{\text {st }}$ research phase conducted through a national on-line survey addressed to all Greek public libraries in October 2018. The survey was carried out by collecting data related to the organization and the design of the library space. In the absence of a weighted survey, a research tool which included closed-ended questions and multiple-choice questions was designed specifically for the needs of the present study $[22,23]$. The rough depiction of the libraries' space design characteristics $\left(1^{\text {st }}\right.$ phase $)$ was followed by a more detailed one ( $2^{\text {nd }}$ phase), through visiting a number of libraries among those included in the initial library list. For the thorough depiction an Observation Checklist was used. The observation tool construction was based on the principles and guidelines of the Early Childhood Environment Rating Scale (ECERS) and other Library assessment tools $[24,25,26]$. For the assessment of space variety, it was decided to rate each individual characteristic with a constant rating. Thus, the answers were coded and serial numbers were used to indicate: a) the absence (coded with number 0), b) the indication needs to be improved (coded with number 1) and c) the existence, (coded with number 2). We chose the ascending order of numbers because a) this corresponds to the presence / provision or not of a service or a feature and b) it facilitates the commentary of the results. The checklist -which may be further enriched with various additional features- was tested, supplemented and used in spring 2019. Finally, in order to capture the type of interaction, the library proposes, we kept field notes (rough floor plans) on the arrangement of tables and chairs and b) on the existence or absence of a place / area suitable for withdrawal. 


\section{Participants}

In the $1^{\text {st }}$ research phase, 235 Greek public libraries listed in the Greek Libraries Network site in the period of research (October 2019) were invited to participate in a national on-line survey.

In the $2^{\text {nd }}$ research phase, a random subset of the libraries having participated in the $1^{\text {st }}$ phase formed the sample of libraries to be visited. The selection of libraries was done by random draws through the list of libraries and in such a way that three categories of space sizes $\left(\left\langle 40 \mathrm{~m}^{2}, 41-79 \mathrm{~m}^{2}\right.\right.$ and $\left.\left.80 \mathrm{~m}^{2}\right\rangle\right)$ were equally represented in both types of library spaces. The size category $<40 \mathrm{~m}^{2}$ of Children's Libraries was not represented as in the list of 32 libraries responding to the $1^{\text {st }}$ phase; this category demonstrated a minor presence (see Table 1). The sample selected is neither probable nor large, but it represents the spread of variations of the entire library population. It is, therefore a set of case studies which will be used to make a generalization to the population they represent [27]. Within each category, stratification is performed in accordance with the size of the libraries with a fixed sample size within each layer [28].

Table 1: Libraries' sample in each space size category

\begin{tabular}{c|c|c|c}
\hline & $\mathbf{< 4 0}^{\mathbf{2}}$ & $\mathbf{4 1 - 7 9 \mathbf { m } ^ { \mathbf { 2 } }}$ & $\left.\mathbf{8 0 m}^{\mathbf{2}}\right\rangle$ \\
\hline Children Departments/Areas & 3 & 3 & 3 \\
Children Libraries & 0 & 3 & 3 \\
\hline
\end{tabular}

\section{FINDINGS}

\subsection{Findings from the implementation of the survey}

192 libraries (160 general user Public Libraries and 32 Children Libraries) participated in the survey (response rate $81.7 \%$ ) out of 235 Greek public libraries listed in the Greek Libraries Network site in the period of research (October 2018). Of the 160 general user public libraries, only 28 did not provide a specially designed and equipped space for children due to lack of space and / or different targeting. The remaining 132 gave provision for children areas in the local public library building which also caters for adults or in a separate accommodation located elsewhere (32 Children's Library). Both types of libraries are designed to serve mainly preschool and elementary school children (see Table 2).

Table 2: Ages of Children Users designed to serve (more than one answers)

\begin{tabular}{c|c|c|c|c}
\hline User groups for whom designed & $\begin{array}{c}\text { Number of Public } \\
\text { Libraries }\end{array}$ & Percentage & $\begin{array}{c}\text { Number of } \\
\text { Children } \\
\text { Libraries }\end{array}$ & Percentage \\
\hline Babies-Toddlers & 22 & $16,7 \%$ & 10 & $31,3 \%$ \\
Preschool children & 108 & $81,8 \%$ & 29 & $93,8 \%$ \\
Elementary school children & 129 & $97,7 \%$ & 31 & $96,9 \%$ \\
Parents \& Caregivers & 84 & $63,6 \%$ & 25 & $78,1 \%$ \\
Users in wheelchairs & 27 & $20,4 \%$ & 7 & $21,9 \%$ \\
Teens & 6 & $4,5 \%$ & 5 & $15,6 \%$ \\
\hline
\end{tabular}

Nearly $73 \%$ of the Public Libraries and $90 \%$ of Children's Libraries stated that they are housed in buildings sized less than $250 \mathrm{~m}^{2}$, which according to the Dewe (2006) library size categorization, suggests these libraries are considered of small size. In Public Libraries, the Children's area occupies only a part of the useful space of the entire library (in average $20 \%$ of the whole space following the general rule of the Greek Guidelines for Library Buildings [29]. Most libraries use the open floor plan design space (76,6\%). Those who don't use it, place the Children's' area separately, e.g., in a separate room, in a mezzanine or other area $(23,4 \%)$. Following the three-range categories of sizes, the current stated picture of library spaces for children is illustrated in Table 3.

Table 3: Common sizes of Children's Library Areas \& Children's Libraries separate provision

\begin{tabular}{c|c|c|c|c}
\hline & $\begin{array}{c}\text { Children's library } \\
\text { areas }\end{array}$ & \% & $\begin{array}{c}\text { Children's } \\
\text { Libraries }\end{array}$ & $\%$ \\
\hline$\left\langle 40 \mathrm{~m}^{2}\right.$ & 97 & $73,49 \%$ & 2 & $6,25 \%$ \\
$41-79 \mathrm{~m}^{2}$ & 23 & $17,42 \%$ & 11 & $34,35 \%$ \\
$80 \mathrm{~m}^{2}>$ & 12 & $9,09 \%$ & 19 & $59,40 \%$ \\
\hline & 132 & $100 \%$ & 32 & $100 \%$ \\
\hline
\end{tabular}


According to their statements, libraries divide spaces for children in smaller functional micro-environments among which the most popular is the area with tables and chairs. Nearly half of the libraries offer a computer area and a carpeted area, while a withdrawal area/position seems to be offered in a few Children Libraries and only in a $6 \%$ of the general user libraries (See Table 4).

Table 4: Micro-environments in children library spaces (common table more than one answers)

\begin{tabular}{c|c|c|c|c}
\hline User ages for whom designed & $\begin{array}{c}\text { Number of Public } \\
\text { Libraries }\end{array}$ & Percentage & $\begin{array}{c}\text { Number of } \\
\text { Children's } \\
\text { Libraries }\end{array}$ & Percentage \\
\hline Table/chair area & 120 & $91 \%$ & 28 & $87,5 \%$ \\
PC area/zone & 57 & $43,2 \%$ & 14 & $43,8 \%$ \\
Carpeted area & 53 & $40,1 \%$ & 16 & $50,0 \%$ \\
Withdrawal areas/positions & 8 & $6 \%$ & 9 & $28,1 \%$ \\
\hline
\end{tabular}

\subsection{Findings from the implementation of the Observation Checklist}

Library Children's spaces appear to have low environment diversity. All spaces are flat. In some cases, non-structured surfaces are offered in the form of reading stairs or a plateau (5.5. \& 6.5). Libraries have mainly a 'hard' dimension. They all provide an area with tables and chairs. The number of tables and chairs is not always low in small size libraries and higher in bigger libraries. Occasionally, the picture is reversed. In Children's areas, it is preferred to offer chairs and tables scaled for preschool children and adult users $(5.7,5.8,5.9)$, while in Children's Libraries, the presence of tables and chairs for preschool children is strong. Less but not negligible is the presence of tables and chairs scaled for the need of elementary school-aged children and grown-ups $(6.7,6.8,6.9)$. A few of the most newly designed libraries use one size fits all stools and tables of the same height for all users, which appear to be unsuitable to use and not ergonomic for most users (Figure 1). Contrary to the hard areas' furniture, the standard size, soft equipment seems to fit all users (Figure 2).
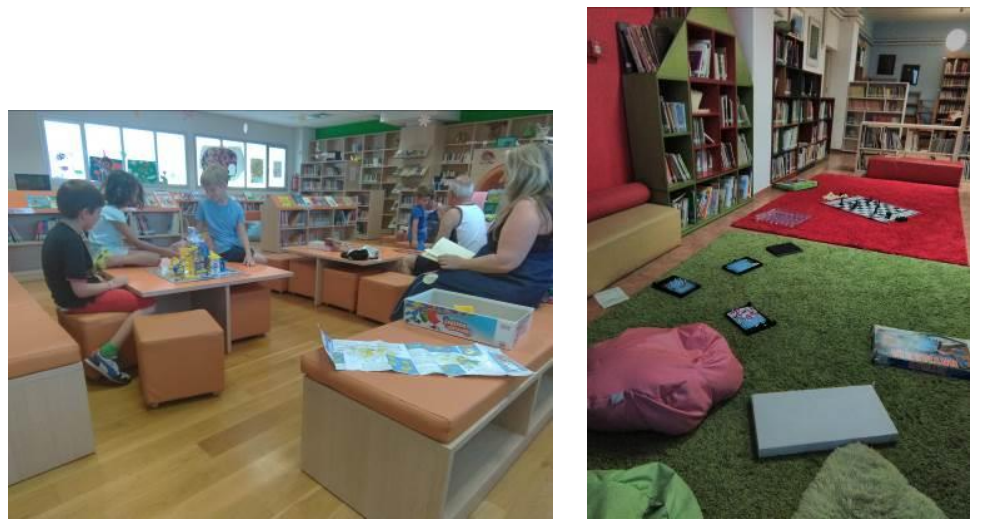

Figure 1: One size fits all stools and tables. The legs of the boy in the left seem pressed, while the other two kids preferred to sit on the table. Figure 2: The soft area is perfectly completed by the low foam benches, suitable for all users in the left and in the background of the picture (Photos taken by the researcher upon permission).

The opportunity to withdraw in an enclosed area was traced only in one library of the smallest group-size. In fact, it was deemed appropriate to place a circus-like tent in the area for one or two children who want to be out of sight for a while (Figure 3). In the same library, an egg shaped IKEA seat was available and ready to host a preschool child who would like to lie in a different type of posture (Figure 4). 

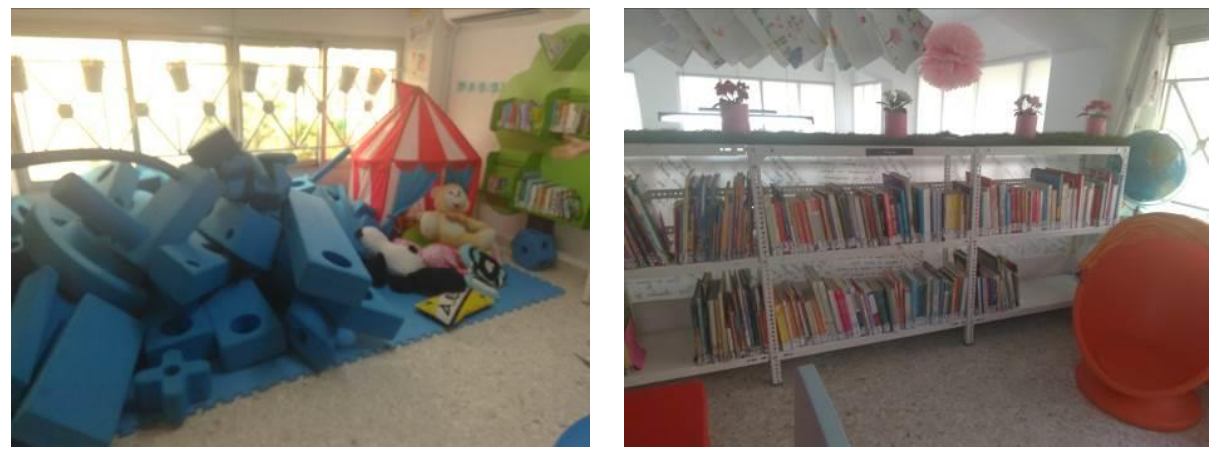

Figure 3: A tent is a suitable withdrawal space. Figure 4: An egg-shaped chair for preschoolers can serve as a withdrawal sitting (Photos taken by the researcher upon permission).

Table 5: Children's areas sitting equipment

\begin{tabular}{|c|c|c|c|c|c|c|c|c|c|}
\hline & \multicolumn{3}{|c|}{$<40 m^{2}$} & \multicolumn{3}{|c|}{$41-79 m^{2}$} & \multicolumn{3}{|c|}{$80 m^{2}>$} \\
\hline & $\begin{array}{c}1^{\text {st }} \\
20 \mathrm{~m}^{2}\end{array}$ & $\begin{array}{c}2^{\text {nd }} \\
28 m^{2}\end{array}$ & $\begin{array}{c}3^{\text {rd }} \\
30 \mathrm{~m}^{2}\end{array}$ & $\begin{array}{c}1^{\text {st }} \\
42 \mathrm{~m}^{2}\end{array}$ & $\begin{array}{c}2^{\text {nd }} \\
67 \mathrm{~m}^{2}\end{array}$ & $\begin{array}{c}3^{\text {rd }} \\
72 \mathrm{~m}^{2}\end{array}$ & $\begin{array}{c}1^{\text {st }} \\
82 \mathrm{~m}^{2}\end{array}$ & $\begin{array}{c}2^{\text {nd }} \\
85 m^{2}\end{array}$ & $\begin{array}{c}3^{\text {rd }} \\
200 \mathrm{~m} \\
2\end{array}$ \\
\hline 5.1 Carpeted area & 0 & 0 & 1 & 0 & 2 & 1 & 0 & 0 & 2 \\
\hline $5.2 \mathrm{Big}$, soft cushions/mattresses & 0 & 0 & 0 & 0 & 2 & 0 & 0 & 0 & 0 \\
\hline 5.3. Small cushions & 0 & 0 & 2 & 1 & 0 & 2 & 0 & 2 & 2 \\
\hline 5.4. Carrels & 0 & 0 & 0 & 0 & 2 & 0 & 0 & 0 & 0 \\
\hline $\begin{array}{l}5.5 \quad \text { Reading stairs/other level-type } \\
\text { structure }\end{array}$ & 0 & 0 & 0 & 0 & 1 & 0 & 0 & 0 & 2 \\
\hline $\begin{array}{l}\text { 5.6. Nooks/places/structures for } \\
\text { withdrawal }\end{array}$ & 0 & 2 & 0 & 0 & 0 & 0 & 0 & 0 & 1 \\
\hline $\begin{array}{l}\text { 5.7. Table-chair scaled for preschool } \\
\text { children }\end{array}$ & 2 & 2 & 2 & 2 & 1 & 2 & 2 & 0 & 2 \\
\hline $\begin{array}{l}\text { 5.8. Table-chair scaled for school age } \\
\text { children }\end{array}$ & 0 & 0 & 0 & 0 & 2 & 0 & 0 & 0 & 2 \\
\hline 5.9. Table-chair scaled for adults & 1 & 2 & 2 & 2 & 2 & 2 & 2 & 2 & 2 \\
\hline $\begin{array}{l}5.10 . \text { Soft seat/sofa/armchair for child \& } \\
\text { adult }\end{array}$ & 0 & 0 & 2 & 0 & 1 & 0 & 0 & 0 & 0 \\
\hline TOTAL & 3 & 6 & 9 & 5 & 13 & 7 & 4 & 4 & 13 \\
\hline
\end{tabular}

Less than half libraries (7/15) offered a carpeted area (5.1 \& 6.1). Only four of them were considered as sufficient soft (4/15). It was noted that a subset of two libraries supported the soft area by offering cushions (Figure 5) or mattresses to facilitate sitting $(5.2,5.3 \& 6.2,6.3)$. Only three provided cushions big enough to serve for comfortable sitting. However, only two of these libraries offered plenty large pillows. The remaining carpets used in the libraries weren't soft enough, nor clean since shoes were permitted. Enough big cushions to enhance a comfortable sitting were provided only by one library (5.2 \& 6.2).

Carrel-type sittings were used by two of the medium sized libraries, placed on wall openings and also by one of the big libraries, placing them in more central positions $(5.4 \& 6.4)$. 


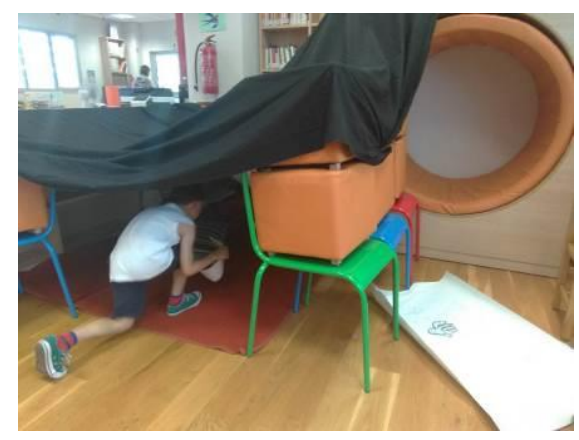

Figure 5: A low pile carpet supported by large soft cushions, turned out to be a soft space for children willing to read or play. Figure 6: The same space transformed to a cave-like space with the use of the available furniture and a black large piece of light. Next to the temporary cave, a carrel sitting is available (Photos taken by the researcher upon permission).

In terms of available sittings, children and caregivers could find a suitable soft sitting for sharing in 2 out of 9 Children's Departments and in 4 out of 6 Children's Libraries (5.10 \& 6.10). Nevertheless, even those sittings in two occasions weren't suitably positioned (e.g., they were placed very close to the entrance of the library), nor had an ergonomic inclination as to offer adults a fine back support. For this they were given a lower grade. The home environment was generally supported in Children libraries by the abundant use of pictures, paintings, decorations, by the presence of colors, by the hanging decorative elements. Plants were rarely used. The same characteristics were present but not to the same extent in general user Public Libraries.

Table 6: Children's Library sitting equipment

\begin{tabular}{|c|c|c|c|c|c|c|}
\hline & \multicolumn{3}{|c|}{ Libraries 41-79m² } & \multicolumn{3}{|c|}{ Libraries 80m² > } \\
\hline & $\begin{array}{c}1^{\text {st }} \\
57 \mathrm{~m}^{2}\end{array}$ & $\begin{array}{c}2^{\text {nd }} \\
70 m^{2}\end{array}$ & $\begin{array}{c}3^{\text {rd }} \\
74 m^{2}\end{array}$ & $\begin{array}{c}1^{\text {st }} \\
110 \mathrm{~m}^{2}\end{array}$ & \begin{tabular}{|c|}
$2^{\text {nd }}$ \\
$148 m^{2}$
\end{tabular} & $\begin{array}{c}3^{\text {rd }} \\
152 \mathrm{~m}^{2}\end{array}$ \\
\hline 6.1. Carpeted area & 0 & 0 & 0 & 2 & 2 & 1 \\
\hline 6.2. Big, soft cushions/mattresses & 0 & 0 & 0 & 0 & 1 & 2 \\
\hline 6.3. Small cushions & 1 & 1 & 0 & 2 & 0 & 1 \\
\hline 6.4. Carrels & 0 & 0 & 0 & 2 & 0 & 2 \\
\hline 6.5 Reading stairs/other level-type structure & 0 & 0 & 0 & 2 & 2 & 0 \\
\hline 6.6. Nooks/places/structures for withdrawal & 0 & 0 & 0 & 0 & 0 & 1 \\
\hline 6.7. Table-chair scaled for preschool children & 0 & 2 & 2 & 1 & 0 & 1 \\
\hline 6.8. Table-chair scaled for school age children & 0 & 2 & 0 & 2 & 0 & 1 \\
\hline 6.9. Table-chair scaled for adults & 2 & 0 & 0 & 2 & 2 & 2 \\
\hline 6.10. Soft seat/sofa/arm-chair for child \& adult & 2 & 0 & 0 & 1 & 2 & 2 \\
\hline TOTAL & 5 & 5 & 2 & 14 & 9 & 13 \\
\hline
\end{tabular}
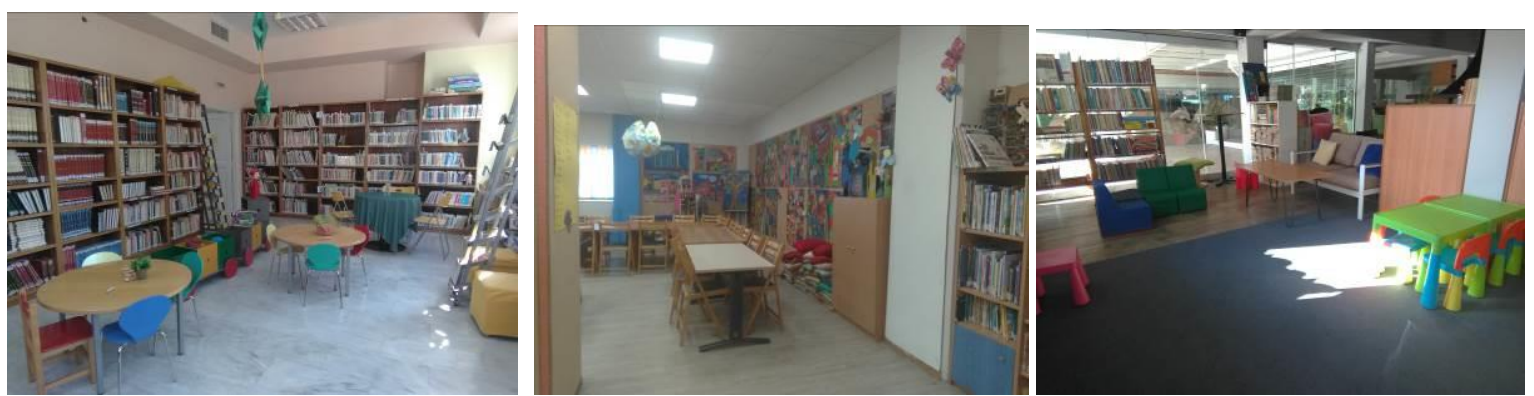

Figure 7: (Left) The promoted arrangement of furniture suits the gathering of small groups in 2 round tables suitable for young children and 1 for adults. Some pouf-sittings in random positions are offered for individual use (Children 
Department $42 \mathrm{~m}^{2}$ ). Figure 8: (Middle) Adult chairs and tables arranged for a large group, small cushions but no carpet available (Children Department $85 \mathrm{~m}^{2}$ ). Figure 9: (Right) A living-room seating area in the background, two tables for up to four preschoolers in the front, plus some scattered seats for individuals (Children Department 30m²) (Photos taken by the researcher upon permission).

In conclusion, the micro-environment for small group interaction is most available in Greek library spaces. In all libraries, individuals or small groups can gather around tables scaled for children or for adults (see Figures 7-9). Carpets, sofas, and auxiliary material for a relaxed body posture such as large cushions and mattresses are less frequently offered, while reading stairs and other level-type surfaces are rarely found. The preferred arrangement of bookcases is against the wall, leaving space for chairs and tables and partly empty spaces for large group gathering. Only two, big in size, Children's Libraries, have used low bookcases and displays as dividers to split the open floor plan remaining space in smaller areas, creating greater visual interest and new space zones.

\section{RESULTS, LIMITATIONS AND FUTURE RESEARCH}

Almost all public Greek library spaces are designed mainly for children 3 to 12 years-old and to a large extent for adults escorting them. Babies, toddlers, teens, and people with mobility disabilities appear to be the most under-served library users. Libraries according to survey findings choose to create mainly hard areas for children, to provide PC's zones, carpet areas and almost none withdrawal spaces. Sitting in hard chairs, next to tables are suggested as a basic type of sitting, while carpeted areas are offered by half of them.

The on-site visit to several of the libraries revealed that library children's spaces aren't so suitably designed and equipped to serve the young users and families. They lack softness and diversity. They promote mainly a hard physiognomy, tables and chairs provided repeatedly. But even when carpeted areas are available, softness is not guaranteed. Carpets are low pale, shoes allowed, soft cushions omitted, unsuitably positioned in the space.

As Tables 5 and 6 acknowledge, the quality characteristics of children's library spaces don't improve as libraries increase in size. On the contrary, it was observed that more square meters don't ensure diversity in space. As Table 5 and 6 indicate, in several characteristics, the larger libraries of the sample did not achieve a higher score. The above findings confirm that the quantitative characteristics of the physical environment do not necessarily ensure its qualitative ones.

Overall, as stated and observed, Children Library Areas and Children Libraries share a common priority: the service of preschool and school aged children up to 12 years old. This is evidenced by the type of seats and tables most of them provide. However, few libraries offer soft areas or soft sittings or materials suitable for comfortable postures to be adopted by users (e.g., soft rags, big cushions, small mattresses etc.). Children and adult can rarely find and use together really comfortable seats together. Sometimes sittings are soft to sit, but not have the right back inclination or they are not suitably spaced. Sometimes the carpet seems a perfect place for children and parents but we must think of those who can't kneel or sit down for different reasons.

Library spaces for children look like adult reading rooms, sometimes like playgrounds and kindergartens, whereas other library spaces do not have a clear identity.

A few exceptions aside, the layouts do not form interesting spaces where children can create their personal spaces and the furniture and the equipment provided is either poor in numbers or in softness. Withdrawal was possible in three libraries, but only one enabled children to hide themselves. The other two permitted only a partially withdrawal in a special type of sitting, the "carrel" type.

The observation of the libraries showed that the design of Children's Library spaces for children does not always go in line with their goal, to offer a hospitable and attractive environment that magnetize users and invite them to stay and come back.

It is assumed that further research is needed on the views of librarian staff about: a) which are the characteristics of a well-designed and a well-equipped library area for children and families and b) which children's developmental needs should libraries prove to serve. Their opinion is crucial because in everyday routine they need to mediate to configure the space needed by library users, but also guide designers to the needs of the public. The methods used, especially the Observation Checklist can be further enriched, standardized and applied to a wider portion of children's libraries.

Given the crucial importance of an early start in children's relationship with reading and use of many and different types of books and other resources, and the need for 'third places' [29] which provide 'edutainment' [30] for all the family members, it is critical to carry out extensive new research upon how libraries can provide better user spaces.

\section{REFERENCES}

[1] Dewe, M., Planning Public library buildings: Concepts and issues for the librarian, Burlington, USA, 2006.

[2] Steele, F. I., Physical Settings and Organization Development. Reading, Massachusetts, USA, 1973.

[3] Rankin, C., IFLA Guidelines for library services for children aged 0-18, IFLA, Netherlands, 2018. 
[4] Germanos, D., Walls of Knowledge, Athens, Greece, 2002 (In Greek).

[5] Anastasakis, M., Redesigning the Library at School: A Proposal for Secondary Education. Greece, 2003.

[6] Arvaniti, I., The school library as a factor of the educational environment dynamics: space and educational process. Unpublished doctoral dissertation, Aristotle University of Thessaloniki, Greece, 2012 (In Greek).

[7] Kostelnik, M. J., Whiren, A. P., Soderman, A. K., Stein, L. C. \& Gregory, K., Guiding children's social development: Theory to practice. Australia, 2002.

[8] Kemple, K. M., Arranging the environment to support peer interaction. In Let's be friends: Peer competence and social inclusion in early childhood programs (pp. 30-54). New York, USA, 2004.

[9] Moore, G.T., The physical environment and cognitive development in child-care centers. In C.S. Weinstein \& T. G. David. (Eds.), Spaces for children: The built environment and child development (pp. 41-67). New York, USA, 1987.

[10] Gibson, J.J., The Ecological Approach to Visual Perception. Boston, USA, 1979.

[11]Curtis, D., Carter, M., Designs for Living and Learning: Transforming Early Childhood Environments. St. Paul, MN: Redleaf Press, 2003.

[12] Berris, R. Miller, E., 'How design of the physical environment impacts early learning: educators' and parents' perspectives", Australasian Journal of Early Childhood vol.36, no 4, pp. 102-110, 2011.

[13] Olds, A. R., "Psychological and physiological harmony in childcare center design", Children's Environments Quarterly, vol. 6, no 4, pp. 8-16, 1989.

[14] Olds, A. R., Child Care Design Guide. New York, USA, 2001.

[15]Feinberg, S., Kuchner, J., Feldman, S., Learning environments for young children: Rethinking Library Spaces and Services. Chicago, IL, USA, 1998.

[16] Blaska, J. K., Hasslen, R., "Environmental impact: What we can learn from Swedish early childhood settings", Day Care and Early Education vol. 21, no 3, pp. 29-33, 1994.

[17] Maslow, A. H., Motivation and personality. New York, USA, 1954.

[18] Chandler, W. L., "A Teacher space or a learner place?: Reconsidering the classroom environment", International Journal of Learning vol.16, no 9, 261-267, 2009.

[19] Proshansky, H. M., Fabian, A. F. The development of place identity in the child. In: C. S. Weinstein \& T. G. David (Eds.), Spaces for Children. The Built Environment and Child Development (pp. 21-40). New York, London, 1987.

[20] Moore, G.T., "Effects of the spatial definition of behavior settings on children's behavior: A quasi-experimental field study", Journal of Environmental Psychology, vol. 6, no 3, pp. 205-23, 1986.

[21] Rankin, C. (Ed.) IFLA Guidelines for Library Services to Children aged 0-18. Den Haag, Netherlands, 2018

[22] Babbie, E. R., The basics of social research. Belmont, CA, USA, 2008.

[23] Cohen, L. Manion, L., Morrison, K., Research methods in education. London; New York, USA, 2000.

[24] Harms, T., Clifford, R. M., Cryer, D., Early childhood environment rating scale. New York, USA, 1998.

[25] Latimer, K., Sommer, D. (Eds.) Post-occupancy evaluation of library buildings. Berlin/Munich, Germany, 2015.

[26] New South Wales State Library People places Post-Occupancy Evaluation, Australia, 2012. https://www.sl.nsw.gov.au/sites/default/files/poe_survey_template.pdf

[27] Robson, C., Real world research: a resource for social scientists and practitioner-researchers. Oxford, UK, 2002.

[28] Ministry of National Education and Religion, Greek Guidelines for Greek Public Library Buildings. Athens, Greece, 2004 (In Greek).

[29] Oldenburg, R., The Great Good Place: Cafes, Coffee Shops, Bookstores, Bars, Hair Salons, and Other Hangouts at the Heart of a Community. New York, USA, 1999.

[30] Aksakal, N., Theoretical view to the approach of the edutainment. Procedia - Social and Behavioral Sciences, vol. 186, pp. 1232-1239, 2015. 